\title{
SÍNDROME DO FILHOTE NADADOR EM AMERICAN BULLY - RELATO DE CASO
}

\author{
(Swimming puppy syndrome in American Bully - case report)
}

1Júlia Meira, ${ }^{2}$ Cinthia Garcia, ${ }^{3}$ ssadora Scherer Borges, ${ }^{4}$ Wesley Renosto Lopes

\begin{abstract}
${ }^{1}$ Médica Veterinária Autônoma, Florianópolis, Santa Catarina, Brasil. ${ }^{2}$ Hospital Veterinário Renata Saccaro, Caxias do Sul, Rio Grande do Sul, Brasil. ${ }^{3}$ Médica Veterinária Autônoma, Palmeira das Missões, Rio Grande do Sul, Brasil. ${ }^{4}$ Clínica Ducão Veterinária, Caxias do Sul, Rio Grande do Sul, Brasil.
\end{abstract}

*Correspondência: meirajuli@gmail.com

RESUMO: A síndrome do filhote nadador ou hipoplasia miofibrilar, corresponde a um transtorno infrequente em pequenos animais decorrente da frouxidão ligamentar principalmente das articulações coxo-femoral e ligamentos escapulares, que afeta principalmente filhotes caninos (NGANVONGPANIT; YANO, 2013). Sua etiologia é desconhecida, mas sabe-se que existem raças predispostas e fatores ambientais e nutricionais que contribuem para o agravamento da doença (YARDIMCl et al., 2009). Os sinais clínicos tornam-se visíveis na segunda ou terceira semana de vida durante o período de aprendizagem da marcha (NGANVONGPANIT; YANO, 2013). O objetivo deste resumo é descrever o caso de um cão, macho, com 50 dias que foi atendido na Clínica Ducão Veterinária, Caxias do Sul/RS, pesando 2,1 kg, da raça American Bully, com diagnóstico sugestivo de síndrome do filhote nadador. $O$ paciente apresentava queixa principal de dificuldade locomotora apresentando abdução dos membros torácicos a partir dos 43 dias de vida. Ao exame físico não houve alterações de parâmetros fisiológicos, bem como no exame ortopédico e neurológico, porém, verificou-se deformidade extensora em membros torácicos, conferindo aspecto de abdução. Diante do histórico e quadro clínico do paciente, suspeitou-se de um possível déficit nutricional e foi instituído tratamento clínico com aplicação intravenosa de cálcio (75 mg/animal), associado a ração super premium e ao uso de suplemento vitamínico e mineral (Cald-Mix $\left.{ }^{\circledR}\right)$. Após cinco dias de tratamento, o paciente não apresentou um resultado satisfatório e solicitou-se exame radiográfico simples de membros torácicos direito e esquerdo, revelando que as linhas de crescimento apresentaram-se discretamente abertas para o esqueleto imaturo correspondente, além de deslocamento cranial do rádio em relação à ulna (bilateral), porém sem indícios de desvio de eixo ósseo, sugerindo possibilidade de hipoplasia miofibrilar. O tratamento prescrito baseou-se em adicionar o uso de bandagem feita de esparadrapos em forma de oito (algemas), mantendo os membros torácicos em posição anatômica ideal e estável. Também foi recomendada fisioterapia com intuito de aumentar o tônus muscular, ativar a coordenação e estimular a mobilidade articular correta. A dieta manteve-se como a indicada inicialmente, atentando-se ao ganho de peso do animal que pode resultar em fragilidade dos membros. Instruiu-se o tutor a manter o paciente em ambiente com piso antiderrapante que contribui de forma relevante para sua recuperação. Em seu primeiro retorno, após 48 horas, o cão apresentou uma melhora significativa, sendo possível apoiar os dígitos de ambos os membros. Ao completar sete dias de tratamento, houve melhora completa, sendo notável deambulação e postura adequada. A síndrome do filhote nadador manifesta uma sintomatologia diversificada, revelando uma origem multifatorial, o que torna difícil a compreensão da etiologia desta afecção. No entanto, as deformações são susceptíveis a regressão com tratamento clínico não invasivo e os pacientes são capazes de voltar a normalidade (YARDIMCl et al., 2009). Em geral, os animais tratados precocemente com acompanhamento periódico, apresentam uma maior chance de regressão das lesões e um melhor desenvolvimento (NGANVONGPANIT; YANO, 2013). O paciente em questão foi diagnosticado e deu início ao tratamento aos 43 dias de vida apresentando uma melhora significativa após sete dias.

Palavras-chave: cão; hipoplasia; locomoção. 


\section{Referências}

NGANVONGPANIT, K.; YANO, T. Prevalence of swimming puppy syndrome in 2.443 puppies during the years 2006 - 2012 in Thailand. Veterinary Medicine International, doi: 10.1155/2013/617803, 2013.

YARDIMCI, C.; ÖZAK, A.; NISBET, H. Ö.; SIRIN, Y. S. Swimming syndrome in two labrador puppies. Kafkas Universitesi Veteriner Fakultesi Dergisi, v. 15, n. 4, p. 637-640, 2009. 